\title{
Cavisoma magnum (Cavisomidae), a unique Pacific acanthocephalan redescribed from an unusual host, Mugil cephalus (Mugilidae), in the Arabian Gulf, with notes on histopathology and metal analysis
}

\author{
Omar M. Amin ${ }^{1, *}$, Richard A. Heckmann², and Majid A. Bannai ${ }^{3}$ \\ ${ }^{1}$ Institute of Parasitic of Diseases, 11445 E. Via Linda \# 2-419, Scottsdale, AZ. 85259, USA \\ ${ }^{2}$ Department of Biology, Brigham Young University, 1114 MLBM, Provo, UT 84602, USA \\ ${ }^{3}$ Marine Vertebrate, Marine Science Center, University of Basrah, Basrah, Iraq
}

Received 11 October 2017, Accepted 18 January 2018, Published online 9 February 2018

\begin{abstract}
Cavisoma magnum (Southwell, 1927) Van Cleave, 1931 was originally described from a sea bass, Serranus sp. and spotted surgeonfish, Ctenochaetus strigosus (Perciformes) off Sri Lanka before its more recent redescription from milkfish in the Philippines in 1995. These reports were based on only light infections of their host fishes. Of the few flathead grey mullets, Mugil cephalus (Mugilidae), that we examined in the Arabian Gulf, one fish was infected with 1,450 worms. One milkfish, Chanos chanos (Chanidae), from the same location in the Arabian Gulf, was also heavily infected with specimens of $C$. magnum. The descriptions of this unique large worm are revised and for the first time, we provide SEM images, new systematic observations, metal analysis of hooks showing extremely high levels of sulfur, and histopathology in the mullet intestinal tissue. Adjustments and corrections of previous descriptive accounts are made. The histopathology studies show extensive damage to the host intestinal tissue including epithelial necrosis, hemorrhaging and worm encapsulation. There is an extensive amount of host connective tissue surrounding the worm. Results of x-ray analysis displayed high levels of sulfur in proboscis hooks, especially at the tips and edges of these attachment structures.
\end{abstract}

Keywords: Acanthocephala, Cavisoma magnum, Mugil cephalus, Chanos chanos, Arabian Gulf, redescription, SEM, histopathology, metal analysis

Résumé - Cavisoma magnum (Cavisomidae), un Acanthocéphale exceptionnel du Pacifique redécrit à partir d'un hôte inhabituel, Mugil cephalus (Mugilidae), dans le golfe Persique, avec notes sur l'histopathologie et l'analyse des métaux. Cavisoma magnum (Southwell, 1927) Van Cleave, 1931 a été décrit à l'origine à partir de spécimens parasites d'un Serranus sp. et du poisson-chirurgien Ctenochaetus strigosus (Perciformes) au Sri Lanka avant sa redescription plus récente à partir de spécimens parasites du chano aux Philippines, en 1995. Ces rapports étaient basés uniquement sur des infections légères de leurs poissons-hôtes. Parmi les quelques mulets à grosse tête, Mugil cephalus (Mugilidae) que nous avons examinés dans le golfe Persique, un poisson était infecté par 1450 vers. Un chano, Chanos chanos (Chanidae), originaire du même endroit dans le golfe Persique, était également fortement infecté par des spécimens de C. magnum. Les descriptions de ce grand ver sont révisées et pour la première fois, nous fournissons des images en MEB, de nouvelles observations systématiques, des analyses des crochets montrant des niveaux extrêmement élevés de soufre, et l'histopathologie dans le tissu intestinal du mulet. Des ajustements et corrections des descriptions précédentes sont effectués. Les études histopathologiques montrent des dommages importants du tissu intestinal de l'hôte, y compris nécrose épithéliale, hémorragie et encapsulation des vers. Une grande quantité de tissu conjonctif de l'hôte entoure le ver. Les résultats de l'analyse par rayons X ont montré des niveaux élevés de soufre dans les crochets du proboscis, en particulier aux extrémités et aux bords de ces structures de fixation.

\footnotetext{
*Corresponding author: omaramin@aol.com
} 


\section{Introduction}

Cavisoma magnum (Southwell, 1927) Van Cleave, 1931 was originally described as Oligoterorhynchus magnus by Southwell [18] from the stomach and pyloric ceca of the sea bass, Serranus sp. Cuvier (Serranidae) (20 worms) and from another bass, the spotted surgeonfish Acanthurus strigosus Bennett (=Ctenochaetus strigosus Bennet) (Acanthuridae) (6 worms) off Negapatam, Ceylon (Sri Lanka). Van Cleave [20] assigned it to the new genus Cavisoma in his new family Oligoterorhynchidae Van Cleave, 1931 later becoming Cavisomidae Meyer, 1932 (= Cavisomatidae Petrochenko, 1956). Cavisoma magnum was subsequently reported in specimens of adult milkfish Chanos chanos (Forsskål) (Chanidae) in the Philippines [6,17]. Some of the information lacking in the original description [18] was addressed in the redescription [2] of specimens from $C$. chanos caught in the southern Philippines. Much remained to be addressed. Milkfish was also found infected with C. magnum in the Arabian Gulf. Our collection of 1,450 worms from one flathead grey mullet, Mugil cephalus Linn. (Mugilidae) in the Arabian Gulf off the Iraqi coast provided the materials to fully describe C. magnum using SEM images, make new systematic observations and metal analysis of hooks, and report histopathology in the mullet intestinal tissue.

\section{Materials and methods}

\section{Collection}

Fishes were purchased at the local fish market in AlFaw City area in southern Iraq, northwest Arabian Gulf $\left(29^{\circ} 58^{\prime} 33^{\prime \prime} \mathrm{N} 48^{\circ} 28^{\prime} 20^{\prime \prime} \mathrm{E}\right)$. The intestine of one of 8 flathead grey mullets, Mugil cephalus examined from the Arabian Gulf off the coast of Basrah, Iraq in January and February, 2017 was infected with 1,450 worms. The fish averaged about $120 \mathrm{~cm}$ in total length. One $130 \mathrm{~cm}$ long milkfish, C. chanos, obtained at the same site on November 14, 2017 was infected with about 350 specimens of $C$. magnum. Chanos chanos was previously reported as a host of C. magnum in the Philippines [6,17].

The intestinal tract was examined under a dissecting scope and many unidentified crustaceans and large acanthocephalans were collected, recorded, and placed in clean plastic bags, chilled, and sent to the Marine Science Center, Basrah University. Worms were stored in $70 \%$ ethanol, gross lesions were recorded, and host tissue samples were fixed in $10 \%$ neutral buffered formalin. Selected samples were shipped to our Scottsdale, Arizona facility for processing and further studies. All data collected, together with digitized images, were stored on a USB for future analysis and examination, as reported in Amin et al. [1].

\section{Study of specimens}

Worms were punctured with a fine needle and subsequently stained in Mayer's acid carmine, destained in $4 \%$ hydrochloric acid in $70 \%$ ethanol, dehydrated in ascending concentrations of ethanol (24 hr each), and cleared in $100 \%$ xylene then in $50 \%$ Canada balsam and $50 \%$ xylene ( $24 \mathrm{hr}$ each). Whole worms were then mounted in Canada balsam. Measurements are in micrometers, unless otherwise noted; the range is followed by the mean values between parentheses. Width measurements represent maximum width. Trunk length does not include proboscis, neck, or bursa. Line drawings were created by using a Ken-A-Vision micro-projector (Ward's Biological Supply Co., Rochester, N.Y.) which uses cool quartz iodine $150 \mathrm{~W}$ illumination. Color-coded objective (10X, 20X, 43X) lenses are used. Images of stained whole mounted specimens were projected vertically on 300 series Bristol draft paper (Starthmore, Westfield, Massachusetts), then traced and inked with India ink. Projected images were identical to the actual specimens being projected. Voucher specimens were deposited in the University of Nebraska's State Museum's Harold W. Manter Laboratory (HWML) collection in Lincoln, Nebraska, USA.

\section{SEM (Scanning Electron Microscopy)}

Samples of parasites that had been fixed and stored in $70 \%$ ethanol were processed following standard methods. These included critical point drying (CPD) in sample baskets and mounting on SEM sample mounts (stubs) using conductive double-sided carbon tape. Samples were coated with gold and palladium for 3 minutes using a Polaron \#3500 sputter coater (Quorum (Q150 TES) www. quorumtech.com) establishing an approximate thickness of $20 \mathrm{~nm}$. Samples were placed and observed in an FEI Helios Dual Beam Nanolab 600 (FEI, Hillsboro, Oregon). Scanning Electron Microscope with digital images were obtained in the Nano lab software system (FEI, Hillsboro, Oregon). Images were taken at various magnifications. Samples were received under low vacuum conditions using $10 \mathrm{KV}$, spot size 2, 0.7 Torr using a GSE detector.

\section{X-ray microanalysis, EDAX (Energy Dispersive Analysis for X-Ray)}

Standard methods were used for preparation, similar to the SEM procedure. Specimens were examined and positioned with the above SEM instrument, which was equipped with a Phoenix energy-dispersive x-ray analyzer (FEI, Hillsboro, Oregon). X-ray spot analysis and live scan analysis were performed at $16 \mathrm{kV}$ with a spot size of 5 , and results were recorded on charts and stored with digital imaging software attached to a computer. The TEAM * (Texture and Elemental Analytical Microscopy) software system (FEI, Hillsboro, Oregon) was used. The data included weight percent and atom percent of the detected elements following correction factors.

\section{Ion sectioning of hooks}

A dual-beam SEM with a gallium (Ga) ion source (GIS) was used for the LIMS (Liquid Ion Metal Source) part of the process. The hooks of the acanthocephalans 
were sectioned using a probe current between $0.2 \mathrm{nA}$ and $2.1 \mathrm{nA}$ according to the rate at which the area is cut. The time of cutting is based on the nature and sensitivity of the tissue. Following the initial cut, the sample also goes through a milling process to obtain a smooth surface. The cut was then analyzed for chemical ions with an electron beam (Tungsten) to obtain an X-ray spectrum. The intensity of the GIS was variable due to the nature of the material being cut.

\section{Histology}

Infected host tissue was fixed in $10 \%$ buffered formalin and after dehydration and blocking, the specimens were processed using standard methods [3,13]. The paraffin blocked tissue was sectioned at 4-6 microns, placed on glass slides and stained with hematoxylin and eosin (HE). Additional sections were stained with Mallory's trichrome to emphasize pathological responses to the parasite [9]. The prepared glass slides were viewed with an LSM laser (Carl Zeiss, Thornwood, New York) equipped compound light microscope with representative pictures taken at varying magnifications with a digital camera. $\mathrm{HE}$ is a standard stain for tissue, whereas Mallory's trichrome helps differentiate granular tissue typical of parasite invasion. The histopathological sections (Figs. 20-25) were selected from a much larger collection of sections on 85 glass slides in RAH's collection.

\section{Results}

The prevalence of infection in the grey mullet in our study was low, 1 of 8 fish. The intensity of infection of one fish with 1,450 large worms was, however, very high. The grey mullets have never previously been reported as hosts of $C$. magnum. The finding of this worm in the Arabian Gulf is also a new and distant geographical record.

Our specimens from grey mullet in the Arabian Gulf provided more information than those described by Southwell [18] and Arthur et al. [2]. The description [18] was incomplete and the redescription [2] corrected many of the earlier problems but had its own inadequacies and oversights, especially regarding the proboscis armature and hook roots, egg anatomy and reproductive system structures in males and females. Differences in the egg shape and the organization of cement glands may also have been related to different host or geographical variables.

\section{Cavisoma magnum (Southwell, 1927) Van Cleave, 1931}

Family: Cavisomidae Meyer, 1932

Genus: Cavisoma Van Cleave, 1931

Type host: Sea bass, Serranus sp.

Other hosts: Spotted surgeonfish, Ctenochaetus strigosus (Bennett) (Perciformes) [15,18], milkfish Chanos chanos (Forsskål) (Chanidae) [2] and this paper, and Siganus lineatus Valenciennes (Siganidae) [7], Grey mullet, Mugil cephalus Linn. (Mugilidae) (new host).

Site of infection. Intestine.
Type locality: Indian Ocean "off Negapatam, Ceylon" [=Negappattinam, India].

Other localities: From an unspecified locality off Ceylon (Sri Lanka) [15,18], the Red Sea [15], Basilan Strait off Zamboanga, Zamboanga del Norte Province, Mindanao Island, Philippines [2], and New Caledonia, South Pacific [7], Al-Faw City area in southern Iraq, northwest Arabian Gulf $\left(29^{\circ} 58^{\prime} 33^{\prime \prime} \mathrm{N} 48^{\circ} 28^{\prime} 20^{\prime \prime} \mathrm{E}\right)$.

Specimens deposited: HWML collection no. 139340. Redescription (Figs. 1-19); specimens from Mugil cephalus, northwest Arabian Gulf.

\section{Redescription of specimens from Mugil cephalus (Figs. 1-19)}

General. With characters of the genus Cavisoma. Trunk long, cylindrical, elongate, without evident pseudosegmentation (Fig. 1) but with notched shallow epidermal annulations. Trunk and shared structures considerably larger in females than in males. Body wall aspinose, with very thick tegument of prominent lacunar system and nucleated cells and well defined inner circular muscle layer (Figs. 6, 13, 14). Epidermis with many micropores (Fig. 15) associated with internal crypts and vary in diameter and distribution in different trunk and other locations. Proboscis oblong, slightly wider in anterior third (Figs. 4, 5, 8), with apical cone, prominent when partially retracted (Fig. 9). Proboscis with 12-13 longitudinal rows of 9-11 hooks each. Cortical surface of hooks with longitudinal grooves (Fig. 10) and with thick sulfur-rich hardened layers at the hook tip and edge (Figs. 11, 26). Hooks and roots of 3 types: (1) Apical hook with horizontal root and prominent opposite lateral manubrium. (2) Next 5 hooks with strong simple, posteriorly directed roots. Fourth hook in a row from anterior most robust (thickest diameter at base) with longest blade and root. (3) Posterior 4 slender hooks with weak abbreviated roots (stubs) and long faint anterior manubria (Fig. 7). Basal hook smallest. Neck prominent, with 2 sensory pores (Figs. 8, 12). Proboscis receptacle double walled, narrowing at posterior end, with cephalic ganglion near its middle. Lemnisci digitiform, usually but not always somewhat shorter than receptacle (Figs. 1, 5).

Male (based on 17 mature adults with sperm). See measurements and counts in Tables 1 and 2. Reproductive system at posterior end of trunk (Fig. 1). Testes oval, in tandem with anterior testis larger than posterior testis. Cement gland 4, anterior gland longest, usually bent anteriorly at posterior end of posterior testis, terminating posteriorly at anterior end of Saefftigen's pouch. Saefftigen's pouch massive, bulboid anteriorly and cylindrical posteriorly (Figs. 1, 2). Bursa round without specialized structures, pores or discs (Fig. 16).

Female (based on 18 specimens, most with eggs). See measurements and counts in Tables 1 and 2. Genital pore terminal (Figs. 6, 17). Two prominent sets of ligaments originating near vagina and fanning anteriorly (Fig. 6). Reproductive system $11.4 \%$ length of trunk. Eggs fusiform with long polar ends and polar prolongation of fertilization membranes (Figs. 3, 19), usually enclosed within ligament sac (Figs. 13, 18). 


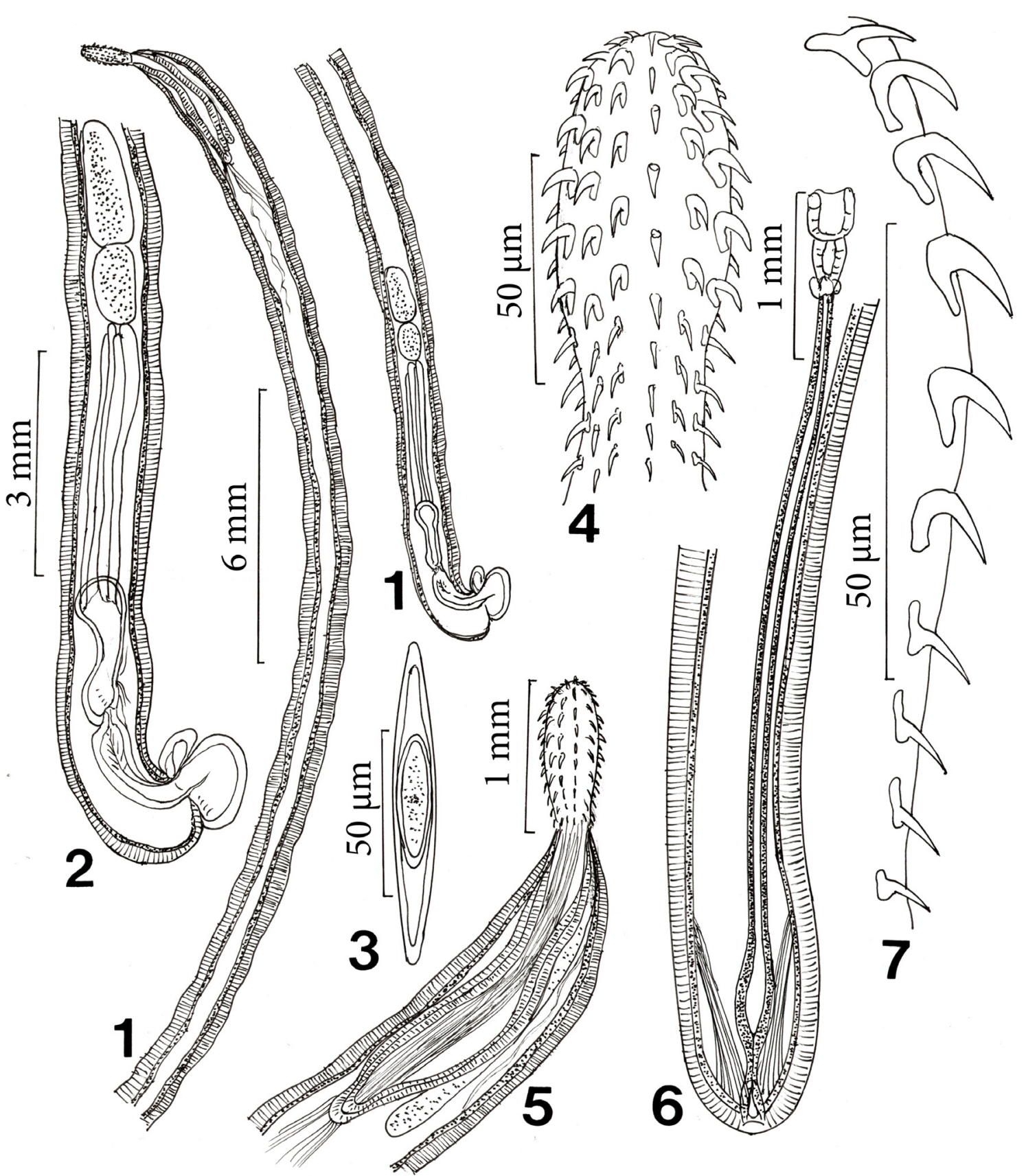

Figures 1-7. Line drawings of specimens of Cavisoma magnum collected from Mugil cephalus in the Arabian Gulf. 1. A male specimen. Note the thick body wall here and elsewhere. 2. The posterior part of the same male in Figure 1 showing the reproductive system. 3. A ripe egg removed from the body cavity. 4. The proboscis of an adult male. 5. The anterior part of the trunk of a male specimen showing the relationship in size and shape of the proboscis, receptacle and lemnisci. 6. Posterior part of the trunk of a female specimen showing the reproductive system. Note the simplified vagina, long uterus, and the two para-vaginal bundles of fanning fibers. 7. One row of proboscis hooks showing three types of hooks/roots, the anterior-most hook with lateral hook with prominent manubrium, the regular subapical hooks with posteriorly directed roots, and the posterior hooks with root stubs and anterior manubria. The hooks and inter-hook spacing are identical to those in actual specimens.

\section{Remarks}

The incompleteness of the information provided in Southwell [18] is reflected in the missing information in Table 1. Additionally, longest hook length in his specimens (sex not stated) was 110 compared to 146 in some of our female specimens. The size of other structures in his material, e.g., proboscis, receptacle, and anterior testis, was also markedly smaller than in our specimens. His specimens were "pseudo-annulated... (Fig. 1) .....probably as a result of contraction." The proboscis in his material was club-shaped bearing 8-10 hooks per row. The proboscis in our specimens was more oblong and with more hooks per row (9-11). The only other descriptive 

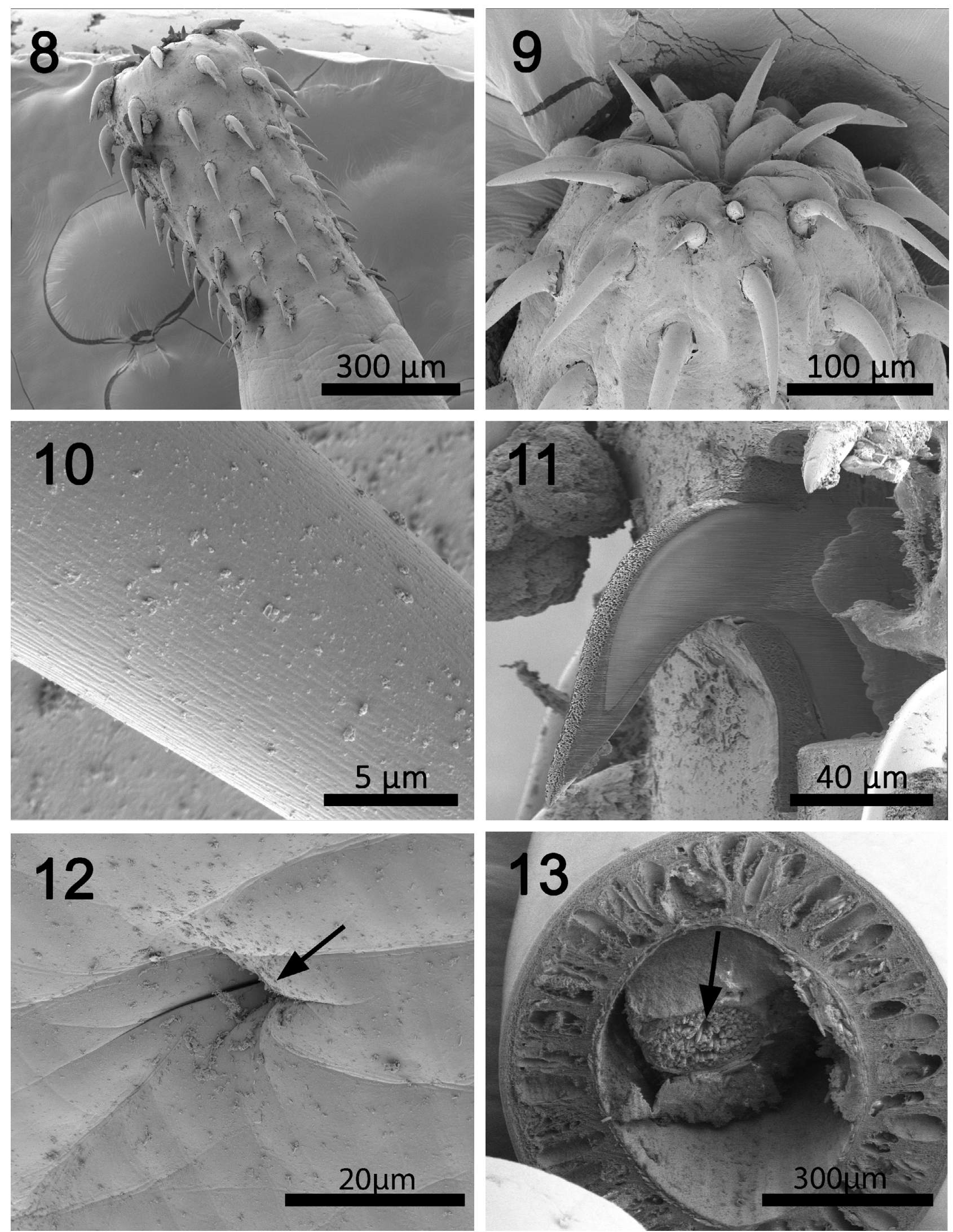

Figures 8-13. SEM of specimens of Cavisoma magnum collected from Mugil cephalus in the Arabian Gulf. 8. A lateral view of a proboscis not fully extended showing one lateral neck sensory pore (arrow). 9. A slightly invaginated apical end of a proboscis showing retracted epidermal cone. 10. A high magnification of a proboscis hook showing the shallow longitudinal serrations on the surface of hooks. 11. A longitudinal gallium cut of a proboscis hook showing the thick sulfur-rich hardened areas at the hook tip and edge (Table 3). 12. High magnification of the neck sensory pore shown in Figure 8. 13. A cross section of a gravid female showing the thick tegument and lacunar canals and a mass of eggs within the ligament sac in the body cavity (arrow). 

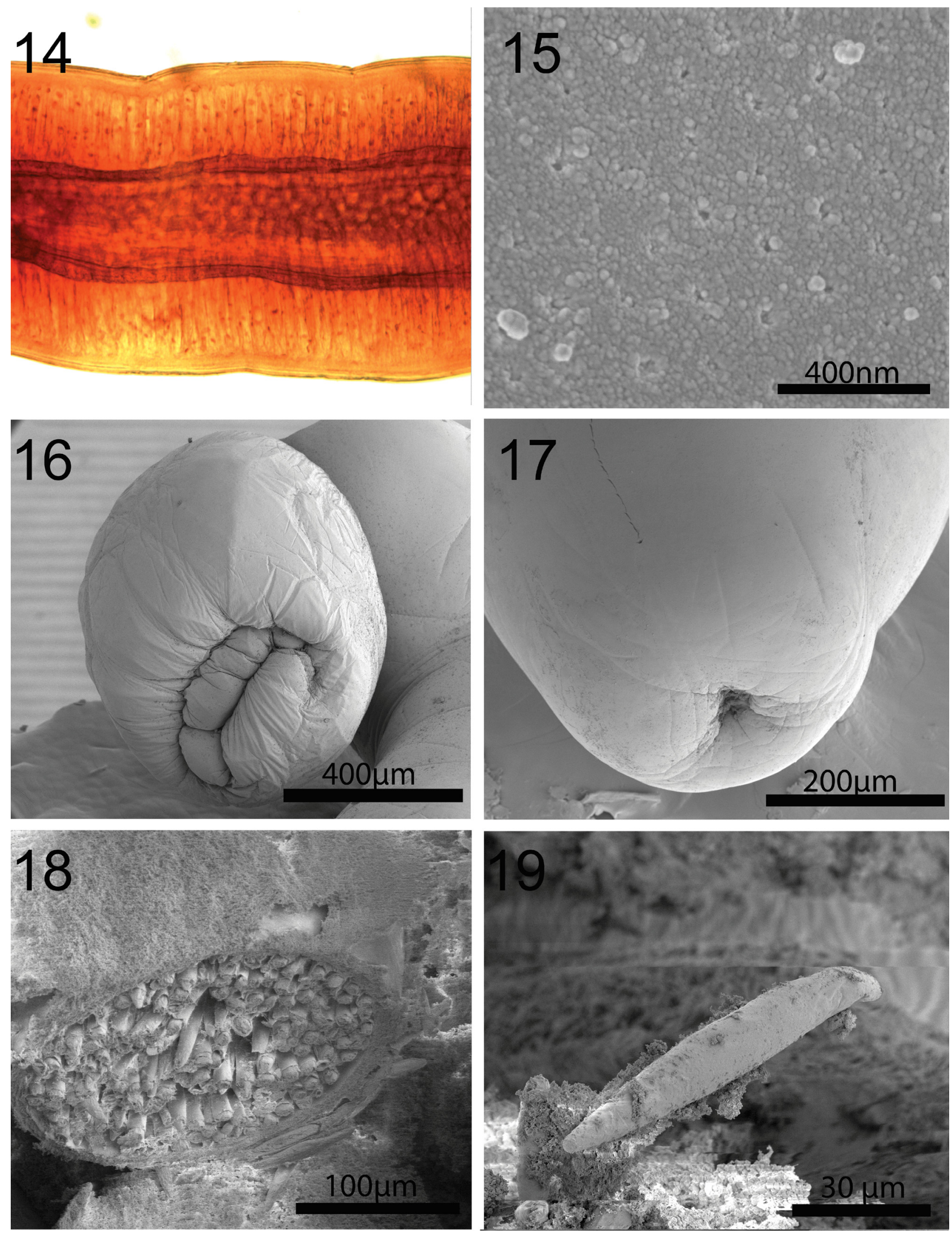

Figures 14-19. SEM and microscopic images of specimens of Cavisoma magnum collected from Mugil cephalus in the Arabian Gulf. 14. A microscopic image of a section of a female specimen showing the outer cuticle, thick tegument and the darker internal circular muscle layer. 15. Epidermal micropores in the posterior trunk section of a worm. 16. A basal perspective of a bursa showing its thick unornamented muscular organization with invagination of its inner orifice. 17. A ventro-lateral view of the terminal female gonopore. 18. A high magnification of packed eggs in the ligament sac of a gravid female. 19. A fully developed ripe egg. 
account of $C$. magnum is that of Arthur et al. [2], whose redescription from Chanos chanos in the Philippines is a considerable improvement over the original description, but varies from ours in the following points. Arthur et al. [2] report 8-10 proboscis hooks per row but their figure 2 shows some hook rows with 6 hooks each. The angle of the single hook root (their fig. 3) is distant from the blade. The egg (their figure 4) appears oblong; the outer shell is actually considerably more prolonged at poles. The female reproductive system (their figure 5) lacks the 2 sets of fanning ligaments originating near the vagina. The posterior end of their male specimen (their figure 6), showed severe pseudo-segmentation in disagreement with their text description. Most significantly, they describe the "Four basal-most hooks in each row" as "rootless." These hooks are actually rooted and the roots have prominent anterior manubria but they are faint and hard to find. Their description makes no reference to the 3 kinds of hook roots of the apical hook, of the other rooted hooks, and of the 4 posterior spiniform hooks. The cement glands do not often reach "the midlevel of Saefftigen's pouch" as stated, and are bundled rather than separate (their fig. 6).

\section{Histopathology}

The results of the histopathological study in M. cephalus are represented by Figures 20 to 25 . The initial tissue fixation did not allow immediate worm response analysis for the host. The proboscis becomes embedded into the connective tissue layers of the host intestine (sub mucosa) with host collagenous fibers attached to the hooks (Fig. 20). The gallium-cut hook demonstrated that the collagenous fibers are closely attached to the solid, multi-layered hook (Fig. 21). A tissue section of the hook-lined proboscis is shown in Figure 23, which is everted from the anterior end of the acanthocephalan (Fig. 22). The next two figures show the depth of worm invasion into the sub-mucosal, connective tissue part of the host intestine (Fig. 24). The trichrome stain preparations (Figs. 24, 25) display the amount of connective tissue in the area, extensive host cell necrosis (Fig. 24), hemorrhaging (Fig. 25) and remnants of the epithelial tissue of the host intestinal mucosa (Fig. 25). The host has generated large amounts of connective tissue. The hemorrhaging is primarily due to the destruction of capillary vessels in the host intestine. The worm, due to its large size and invasive properties, appears to be very destructive to the host intestinal tissue.

\section{X-Ray elemental analysis (EDAX)}

The results of the $\mathrm{x}$-ray elemental analysis are given in Table 3 and Figures 26 and 27. Due to the thickness of the worm body, a scan was taken of that area which demonstrated common protoplasmic elements. Scans were completed for the hook and then 4 positions on the hook cut by a gallium beam. High levels of sulfur were observed in the hook tip (43.51 wt. \%) and edges (27.46wt. \%), which is not characteristic of other acanthocephalan hooks. This was also displayed by the overall hook (17.3 wt. \%) scan. The center and base of the hook did not have high levels of sulfur but contained mostly phosphorus and calcium, two other essential elements for hook structure (Fig. 27). The thickness of the hook outer layer with high levels of sulfur and solid nature of the hooks is displayed by Figure 11 and by the spectrum print out (Fig. 26).

\section{Discussion}

While the prevalence of infection in the grey mullet from the Arabian Gulf was low (1 of 8 fish infected), the intensity of infection of one fish with 1,450 large worms was very high, suggesting that grey mullets are also natural hosts of $C$. magnum, which has never previously been reported. One milkfish also examined in the Arabian Gulf in November, 2017 was heavily infected with specimens of $C$. magnum. These findings suggest that the Arabian Gulf may be another endemic habitat for this parasite, in addition to the South Pacific and the Indian Ocean where earlier accounts report lighter infections. Southwell (1927) collected 26 worms from two species of bass; 20 worms from Serranus sp. and 6 worms from Ctenochaetus strigosus (Perciformes) off Sri Lanka; host numbers and month of collection were not reported but the paper was received for publication on March 31, 1927. Arthur et al. [2] found 30 and 32 worms in two of 5 examined milkfish off the Philippines on March 23, 1987. One other study of spermiogenesis in C. magnum was carried out on 7 specimens collected from one out of 6 (16\%) naturally infected golden-lined spinefoot fishes, Siganus lineatus Valenciennes (Siganidae), off New Caledonia, South Pacific [7].

The flathead mullet is cosmopolitan in coastal waters of the tropical and temperate zones of all seas at temperatures between 8 and $24^{\circ} \mathrm{C}[8,14]$. It occupies fresh, brackish and marine habitats at depths ranging between 0-120 m over sandy or muddy bottoms and dense vegetation [4], and feeds on zooplankton as juveniles and on algae, detritus and small invertebrates as adults [10]. The continuity of the distribution of $C$. magnum from the Pacific to the Indian Ocean to the Arabian Gulf must include a presence in the Red Sea. A confirmation of this supposition was found in Parukhin [15]. In their 7 extensive expeditions collecting parasites of southern commercial marine fishes from Vietnam, Africa, the Red Sea, the Indian Ocean, and the Mediterranean between 1959 and 1973, an international team of scientists reported C. magnum in the Red Sea from the gut of 2 specimens of Acanthurus sp. (4-5 worms), as well as from Serranus sp. and "Acanthurus strigosus" in Sri Lankan waters [15].

\section{Histopathology}

Cavisoma magnum, due to its invasive properties, causes extensive damage to the host intestine. The wellequipped proboscis penetrates through the outer host mucosa and attaches to the lower connective tissue 

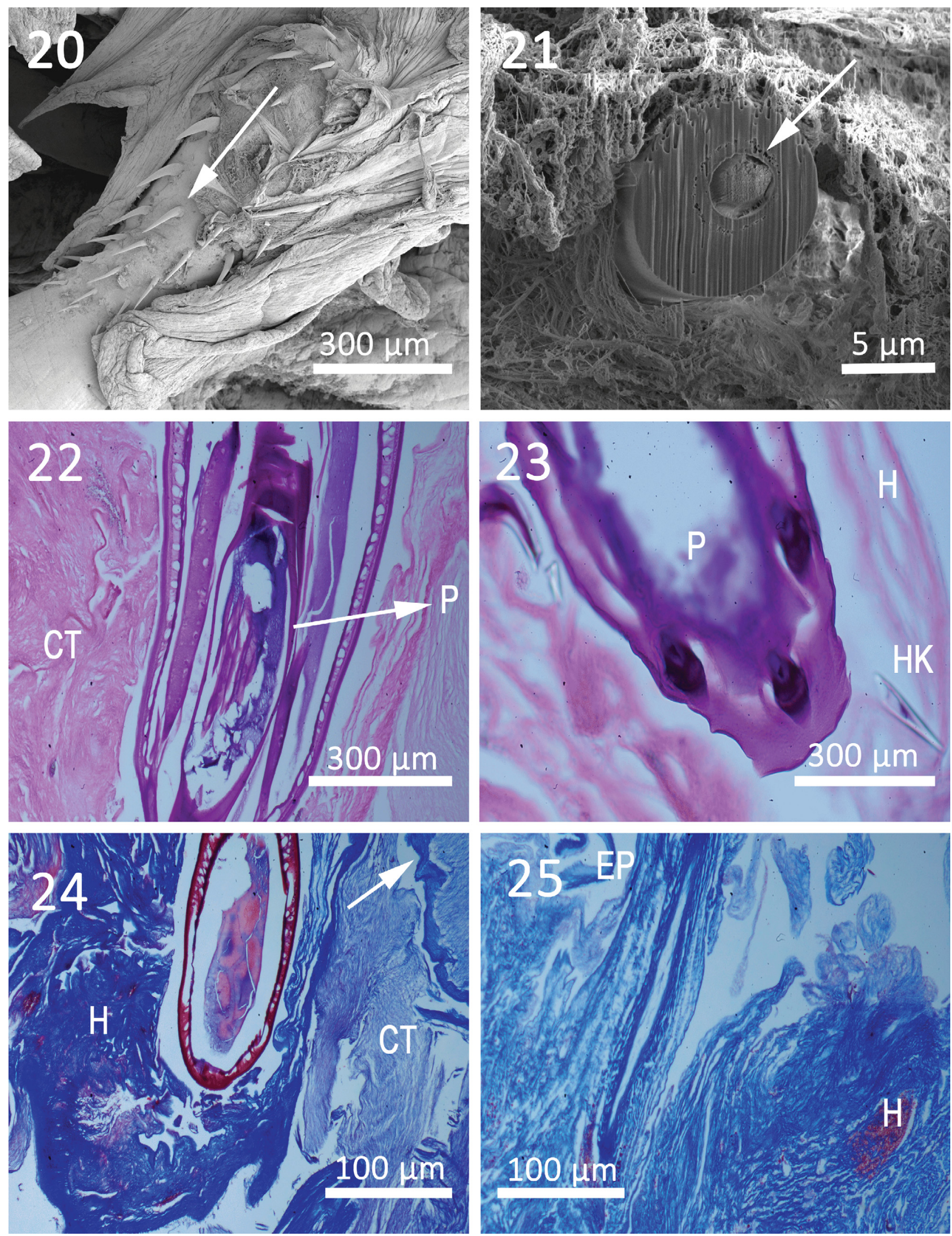

Figures 20-25. Histopathology of Cavisoma magnum in the intestinal track of Mugil cephalus from the Arabian Gulf. 20. SEM of attached worm; note hooks (arrow) on the proboscis of a worm. This image shows the gross pathology and the extreme damage to host intestinal tissue. 21. Gallium-cut hook (arrow) from proboscis of attached worm. Note host connective tissue surrounding worm. 22. Proboscis $(\mathrm{P})$ of a worm. Host connective tissue (CT) is visible with remnants of the intestinal epithelium next to the worm. 23. Proboscis $(\mathrm{P})$ of a worm with sections of worm hooks $(\mathrm{HK})$ and host tissue $(\mathrm{H})$ surrounding worm. 24. Trichrome preparation of infected host tissue $(\mathrm{H})$ section and worm body are visible. Note remnants of host intestine (arrow). 25. Area where worm had infected the host tissue (H). Note ports of hemorrhaged blood caused by worm penetration and remnants of the host intestinal epithelium (EP). 


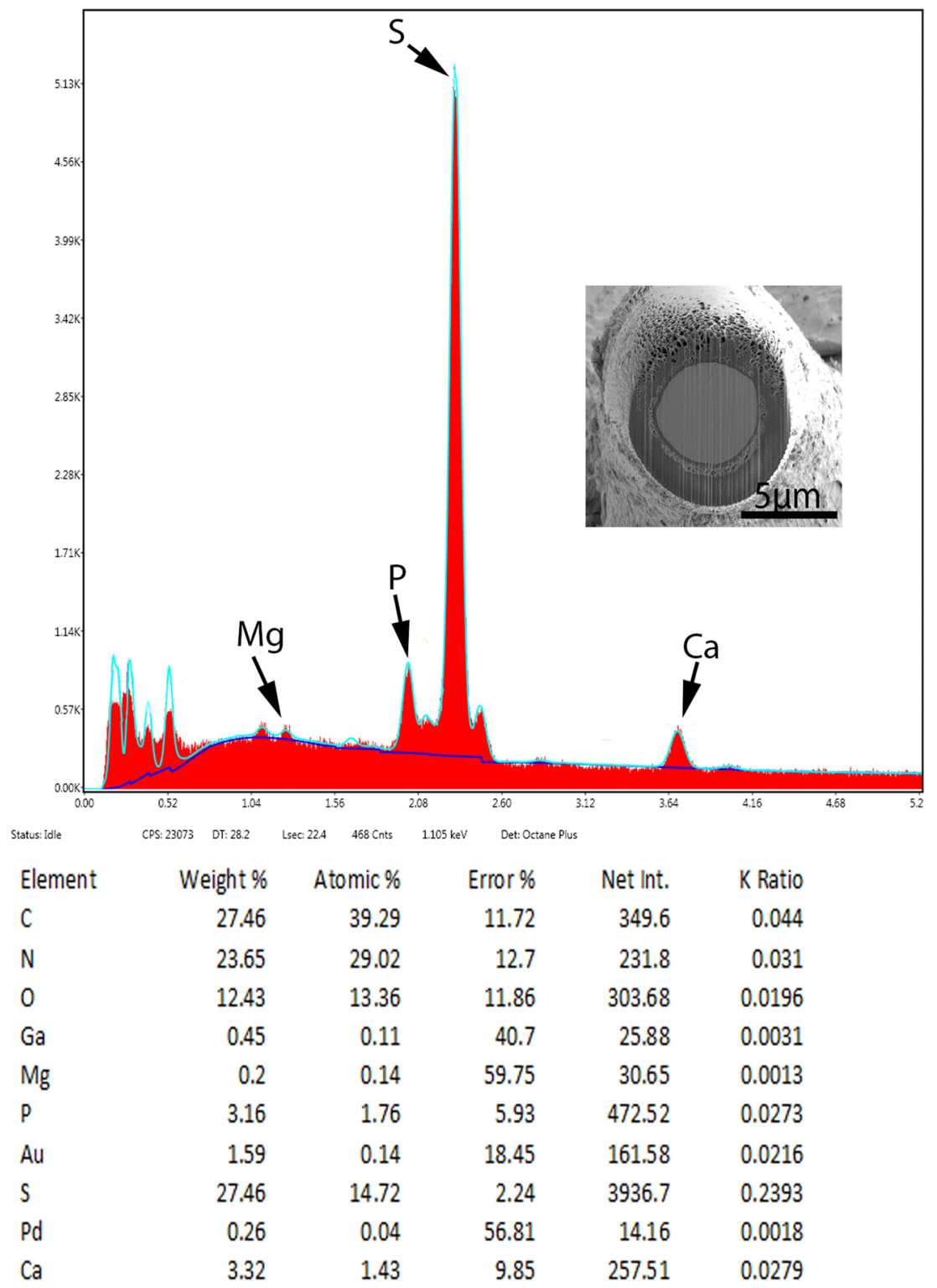

Figure 26. X-ray elemental scan (XEDS) of a Cavisoma magnum hook. Edge of a gallium cut showing high sulfur content. Insert: SEM of cross gallium cut hook.

submucosa. Collagenous fibers from the host surround the proboscis of the worm and attempt to encapsulate and isolate the acanthocephalan (Fig. 26). Hemorrhaging of capillary vessels and extensive cell necrosis follow the invasive path of the worm. The histopathology results are similar to others described by Amin et al. [1] and Heckmann et al. [12].

\section{X-ray scans}

The X-ray scans for Cavisoma magnum displayed a unique mineralization pattern for the hooks with excessive amounts of sulfur on the outer layer of the attachment structure (Fig. 13, Table 3). The other major elements for acanthocephalan hooks and protoplasm were present $[5,11,19]$. The hardened outer layer of the hooks may account for the difficulty for infected host tissue slide preparation. The sulfur ions are found in disulfide bonds linking the amino acid cysteine in the hardened protein. These bonds, in conjunction with $\mathrm{Ca}$ and $\mathrm{P}$ present in the $\mathrm{X}$-ray scans, form the hardened apatite like mammalian tooth enamel [16]. Using gallium cut hooks, the progression of the hook minerals was followed from the tip to the base of the attachment organ.

Acknowledgements. This project was supported by the Department of Biology, Brigham Young University (BYU), Provo, Utah, and by an Institutional Grant from the Parasitology Center, Inc. (PCI), Scottsdale, Arizona. We thank Naomi Mortensen, Bean Museum (BYU) for expert help in the preparation and organization of plates and figures, and Michael Standing, Electron Optics Laboratory (BYU), for his technical help and expertise. We are grateful to the Histology Laboratory, Utah Val-ley Regional Medical Center, Mike Downey Director, 
Table 1. A comparison of morphometric accounts of Cavisoma magnum.

\begin{tabular}{|c|c|c|c|}
\hline & Southwell, 1927 [18] & Arthur et al., 1995 [2] & This paper \\
\hline Males & $\mathrm{N}=20$ males \& females & $\mathrm{N}=15$ & $\mathrm{~N}=17$ \\
\hline Trunk L x W & up to $36.00 \times 1.00$ & $19.42-51.36(35.37) \times 0.73-1.53(1.25)^{*}$ & $29.25-48.75(39.20) \times 1.02-1.35(1.18)$ \\
\hline Neck L x W & - & $0.25-0.40(0.31) \times 0.46-0.50(0.48)$ & $0.26-0.52(0.42) \times 0.42-0.55(0.51)$ \\
\hline Proboscis L x W (0.36) & $1.10 \times 0.45$ & $0.91-1.05(0.97) \times 0.33-0.48(0.39)$ & $1.02-1.27(1.13) \times 0.32-0.45(0.36)$ \\
\hline \multicolumn{4}{|l|}{ Hooks } \\
\hline Long. rows $\mathrm{x}$ hooks/row & $12 \times 8-10$ & $12-13 \times 9-10$ & $12-13(12.6) \times 9-11(10)$ \\
\hline Longest \& basal/hooks & ca $110 \& 70 \mu \mathrm{m}$ & $105-125(116) \& 70-90(80) \mu \mathrm{m}$ & $125-127(126) \& 67-92(85)$ \\
\hline Receptacle L x W & $2.60 \mathrm{x}-$ & $1.23-3.09(2.60) \times 0.34-0.52(0.44)$ & $2.37-3.55(3.00) \times 0.26-0.50(0.39)$ \\
\hline Lemnisci L x W & shorter than proboscis & $1.46-4.05(12.60) \times 0.25-0.58(0.37)$ & $1.66-3.75(2.75) \times 0.09-0.27(0.17)$ \\
\hline Ant. testis $\mathrm{L} \times \mathrm{W}$ & $1.17 \times 0.10$ & $0.70-2.53(1.42) \times 0.25-2.09(0.56)$ & $1.12-1.87(1.35) \times 0.30-0.52(0.40)$ \\
\hline Post. Testis L x W & $1.03 \times 0.10$ & $0.60-1.49(1.04) \times 0.24-0.94(0.51)$ & $0.75-1.62(1.02) \times 0.30 \times 0.55(0.44)$ \\
\hline Cement gland L x W & $3.25 \mathrm{x}-$ & $1.52-4.49(2.99) \times 0.06-0.27(0.17)$ & $1.70-4.62(2.79) \times 0.06-0.25(0.16)$ \\
\hline Saefftigens pouch L x W & - & $1.28-2.85(2.16) \times 0.39-0.98(0.62)$ & $\begin{array}{l}1.37-2.37(2.02) \times 0.45-0.57(0.50) \\
\text { anteriorly }\end{array}$ \\
\hline \multicolumn{4}{|l|}{ (0.32) posteriorly } \\
\hline Females & $\mathrm{N}=20$ males \& females & $\mathrm{N}=16$ & $\mathrm{~N}=18$ \\
\hline Trunk L x W & up to $70.00 \times 1.50$ & $10.67-48.93(30.21) \times 0.54-1.89(1.11)$ & $37.00-66.25(50.95) \times 0.95-1.75(1.36)$ \\
\hline Neck L x W & - & $0.19-0.44(0.25) \times 0.43-0.57(0.50)$ & $0.31-0.57(0.45) \times 0.42-0.73(0.58)$ \\
\hline Proboscis L $\mathrm{x} W$ & $1.10 \times 0.45$ & $0.79-1.08(0.95) \times 0.32-0.43(0.37)$ & $1.04-1.25(1.14) \times 0.34-0.43(0.38)$ \\
\hline \multicolumn{4}{|l|}{ Hooks } \\
\hline Long. rows x hooks/row & $12 \times 8-10$ & $12 \times 8-9$ & $12-13(12.3) \times 10$ \\
\hline Longest \& basal hook & $110 \& 70 \mu \mathrm{m}$ & $105-130(115) \& 65-95(80) \mu \mathrm{m}$ & $130-146(134) \& 77-104(91)$ \\
\hline Receptacle L x W & $2.60 \mathrm{x}-$ & $1.57-3.21(2.30) \times 0.23-0.63(0.42)$ & $2.42-3.55(3.12) \times 0.34-0.50(0.44)$ \\
\hline Lemnisci L x W & shorter than proboscis & $1.58-4.14(2.72) \times 0.13-0.44(0.25)$ & $2.62-3.87(3.28) \times 0.16-0.37(0.25)$ \\
\hline Reproductive syst. L & - & - & $5.82-5.87(5.85)$ \\
\hline Eggs L x W & up to $120-130 \times 22 \mu \mathrm{m}$ & $103-121(113) \times 15-20(17) \mu \mathrm{m}$ & $100-120(106) \times 11-21(15)$ \\
\hline Hosts & $\begin{array}{l}\text { Ctenochaetus strigosus } \\
\text { serranus } \mathrm{sp}\end{array}$ & Chanos chanos & Mugil cephalus \\
\hline Locality & $\begin{array}{l}\text { Indian Ocean off southern } \\
\text { India and Sri Lanka }\end{array}$ & Basilian Strait, Philippines & Arabian Gulf off Iraq \\
\hline
\end{tabular}

\footnotetext{
Range (mean) length $\mathrm{x}$ width in mm, unless otherwise noted.
}

Table 2. Measurements of proboscis hooks and roots of Cavisoma magnum from Mugil cephalus in the Arabian Gulf.

\begin{tabular}{|c|c|c|c|c|c|c|}
\hline \multirow[b]{2}{*}{ Hook no. } & \multicolumn{2}{|c|}{ Hook length } & \multicolumn{2}{|c|}{ Hook thickness at base } & \multicolumn{2}{|c|}{ Root length } \\
\hline & Males & Females & Males & Females & Males & Females \\
\hline 1 & $95-107(100)^{*}$ & $95-115(107)$ & $17-30(24)$ & $20-40(27)$ & $47-55(51)^{* *}$ & $49-60(53)$ \\
\hline 2 & $110-120(116)$ & $115-127(121)$ & $27-42(34)$ & $27-46(37)$ & $65-100(77)$ & $70-110(88)$ \\
\hline 3 & $115-127(116)$ & $120-132(126)$ & $30-55(46)$ & $39-50(43)$ & 80-112 (93) & $80-110(96)$ \\
\hline 4 & $125-127(126)$ & $130-146(134)$ & $40-47(43)$ & $45-52(51)$ & $87-120(100)$ & $95-120(105)$ \\
\hline 5 & $124-125(124)$ & $117-135(129)$ & $30-40(35)$ & $40-52(45)$ & $80-87(83)$ & $95-114(100)$ \\
\hline 6 & $112-120(117)$ & $112-138(122)$ & $20-30(25)$ & $32-42(38)$ & $62-75(70)$ & $75-97(89)$ \\
\hline 7 & $97-117(109)$ & $107-130(119)$ & $17-20(19)$ & $20-27(25)$ & $-{ }^{* * *}$ & - \\
\hline 8 & $87-112(105)$ & $92-125(109)$ & $15-20(17)$ & $22-30(23)$ & - & - \\
\hline 9 & 75-107 (93) & 87-114 (99) & $15-17(15)$ & $20-22(21)$ & - & - \\
\hline 10 & $67-92(85)$ & $77-104(91)$ & $12-15(13)$ & $15-22(18)$ & - & - \\
\hline
\end{tabular}

\footnotetext{
* Range (mean) in $\mu \mathrm{m}$ in 4 males and 4 females.

** Anterior hook root with anterior manubrium about as long as root oriented laterally.

*** Roots of posterior 4 hooks are abbreviated but have long anterior manubria.
} 


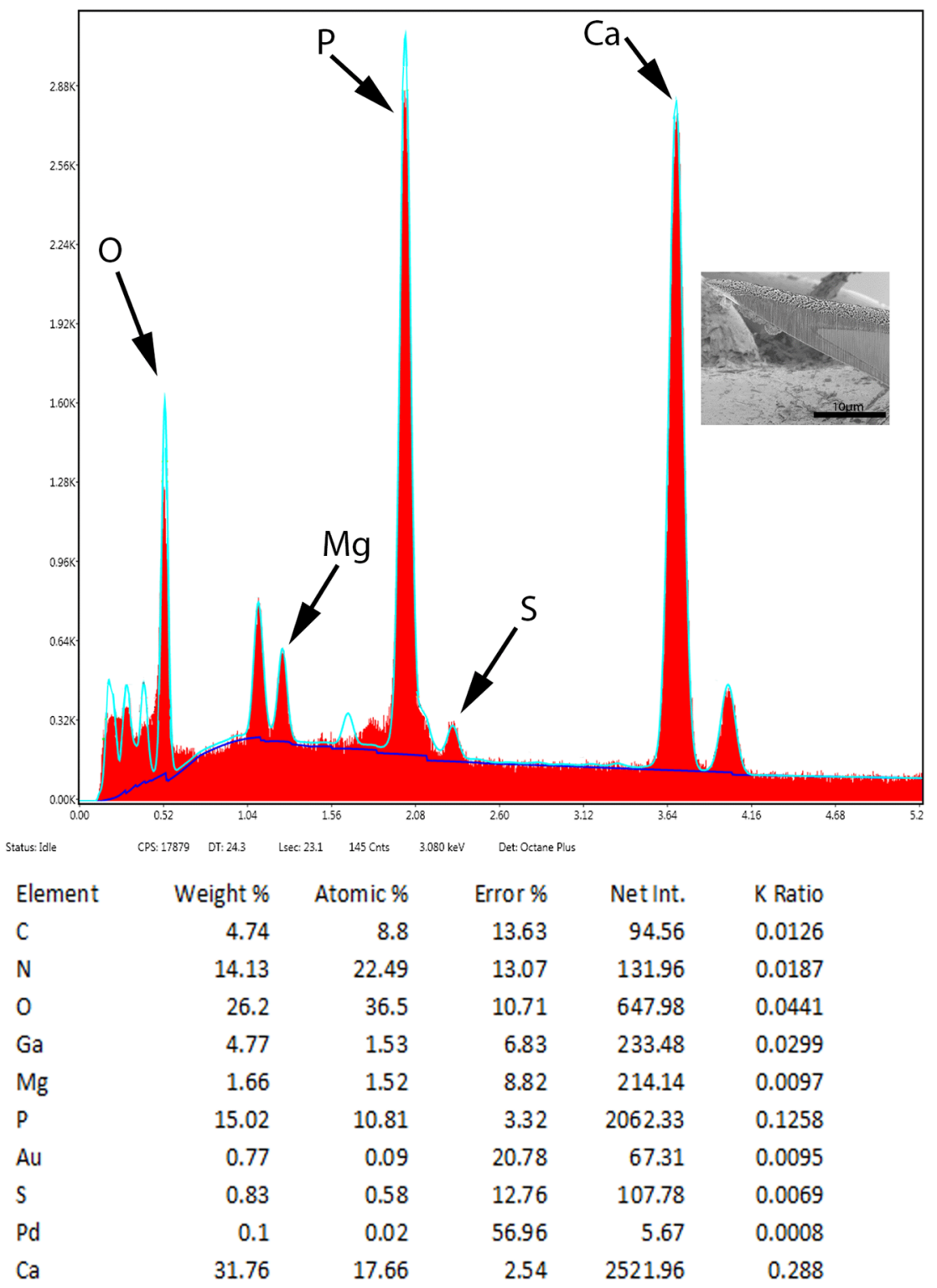

Figure 27. X-ray elemental scan (XEDS) of a Cavisoma magnum hook. Center base of a longitudinal gallium cut showing typical levels of phosphorus, calcium and sulfur content.

Insert: SEM of a longitudinal gallium-cut hook.

Table 3. X-Ray scans for hooks and trunk of Cavisoma magnum from Mugil cephalus.

\begin{tabular}{lllllll}
\hline & Trunk & Hook & Hook tip & Hook mid cut edge & Hook mid cut center & Hook base \\
\hline $\mathrm{P}$ (Phosphorus) & 1.20 & 3.14 & 4.74 & 3.16 & 21.44 & 15.02 \\
S (Sulphur) & 1.68 & 17.30 & 43.51 & 27.46 & 0.97 & 0.83 \\
$\mathrm{C}$ (Calcium) & 0.68 & 3.34 & 5.66 & 3.32 & 39.30 & 31.76 \\
$\mathrm{Mg}$ (Magnesium) & $\mathrm{n}^{* *}$ & $\mathrm{n}$ & $\mathrm{n}$ & $\mathrm{n}$ & $\mathrm{n}$ & 1.66 \\
\hline
\end{tabular}

${ }^{*}$ Four chemical elements are listed by weight percent (wt. \%) for area. Common elements in living cells (H, O, N) and coating and cutting elements $(\mathrm{Pd}, \mathrm{Au}, \mathrm{Ga})$ are not listed.

$\mathrm{n}=$ negligible amount

for the histopathology slide preparation. The contributions of Mr. Essa Taha Mohammad at the Marine Science Center, University of Basrah, Iraq were indispensable for the success of the field work.

\section{Conflict of interest}

The authors declare that they have no conflicts of interest in relation to this article. 


\section{References}

1. Amin O.M., Heckmann RA, Mohamed O, Evans RP. 2016. Morphological and molecular descriptions of Moniliformis saudi sp. n. (Acanthocephala: Moniliformidae) from the desert hedgehog Paraechinus aethiopicus (Ehrenberg) in Saudi Arabia, with a key to species and notes on histopathology. Folia Parasitologica, 63, 14.

2. Arthur JR, Regidor SE, Albert E. 1995. Redescription of Cavisoma magnum (Southwell, 1927) (Acanthocephala: Cavisomidae) from the milkfish, Chanos chanos, in the Philippines. Journal of the Helminthological Society of Washington, 62, 39-43.

3. Bancroft JD, Gamble M. 2001. Theory and practice of histological techniques, 5th ed. Churchill Livingston, Edenborough, U.K., 1-800.

4. Bester C. 2004. Florida Museum of Natural History, Mugil cephalus. http://www.flmnh.ufl.edu/fish/Gallery/Descript/ StripedMullet/StripedMullet.html, downloaded on 16 October 2016.

5. Brazoa T, Poddubnaya LG, Miss NR, Hanzelova V. 2014. Ultrastructure and chemical composition of the proboscis hooks of Acanthocephalus lucii (Müller,1776) (Acanthocephala: Palaeacanthocephala) using X-ray elemental analysis. Folia Parasitologica 61, 549-557.

6. Briones JCA, Papa RDS, Cauyan GA, Urabe M. 2015. The first report of three acanthocephalan parasite species from Philippine fishes. Helminthologia, 52, 384-389.

7. Foata J, Quitichini Y, Justine J-L., Bray RA, Marchand B. 2012. Ultrastructural study of spermiogenesis and the spermatozoon of Cavisoma magnum (Southwell, 1927) (Acanthocephala: Palaeacanthocephala, Cavisomidae), from Siganus lineatus (Pisces, Teleostei, Siganidae) (Valenciennes, 1835) in New Caledonia. Micron, 43 (2-3), 141-149.

8. Froese R, Pauly, D. 2014. Editors Fish Base. "Mugil cephalus" World Wide Web Electronic publication www. fishbase.org, version April 2014.

9. Galigher AE, Kozloff EN. 1971. Essentials of practical micro-technique, 2nd ed. Lee and Febiger, Philadelphia, Pennsylvania, 1-531.
10. Harrison IJ, Senou H. 1999. Mugilidae. In: Carpenter, K. E., Niem, V. H. (Eds.), FAO Species Identification Guide for Fishery Purposes. The Living Marine Resources of the Western Central Pacific vol. 4. Bony Fishes Part 2 (Mugilidae to Carangidae). FAO, Rome pp. 2069-2108.

11. Heckmann RA, Amin OM, Radwan NAE, Standing MD, Eggett DL, El Naggar AM. 2012. Fine structure and Energy Dispersive X-ray Analysis (EDXA) of the proboscis hooks of Rhadinorynchus ornatus, Van Cleave 1918 (Rhadinorynchidae: Acanthocephala). Scientia Parasitologica 13, 37-43.

12. Heckmann RA, Amin OM, Khan A. 2015. Histopathology of Centrorhynchus globirostris (Acanthocephala: Centrorhynchidae) infecting the intestine of the pheasant crow, Centropus sinensis (Stephens) in Pakistan. Scientia Parasitologica 16: 151-155.

13. Keirnan JA. 2002. Histological and histochemical methods: theory and practice. Churchill Livingston, Edingburgh, UK, $1-520 \mathrm{p}$.

14. Minckley WL. 1973. Fishes of Arizona. Arizona Game and Fish Department, Phoenix, 257-258.

15. Parukhin AM. 1976. Parasitic worms of commercial fish of the southern seas. Kiev, Naukova Dumka, 1- 184 p.

16. Raynaud S, Champion E, Benache- Assollant D, Thomas P. 2000. Calcium phosphate apatites with variable $\mathrm{Ca}, \mathrm{P}$ atomic ratio synthesis, characterization and thermal stability of powder. Biomaterials 23: 1065-1072

17. Regidor SE, Arthur JR. 1992. A survey of the parasite fauna of milkfish, Chanos chanos (Forskal), in the Philippines. Pages 313-322 in M. Shariff, R. P. Subasinghe, and J. R. Arthur, eds, Diseases in Asian Aquaculture I. Fish Health Section, Asian Fisheries Society, Manila, Philippines.

18. Southwell T 1927. New species of Acanthocephala (Oligoterorhynchus magnus) from a marine fish. Annals of Tropical Medicine and Parasitology, 21, 165-169.

19. Standing, MD, Heckmann RA. 2014. Features of Acanthocephalan hooks using dual beam preparation and XEDS phase maps. Poster Number 0383- 00501.

20. Van Cleave HJ. 1931. New Acanthocephala from fishes of Mississippi and a taxonomic reconsideration of forms with unusual numbers of cement glands. Transactions of the American Microscopical Society 50, 348-363.

Cite this article as: Amin OM, Heckmann RA, Bannai MA. 2018. Cavisoma magnum (Cavisomidae), a unique Pacific acanthocephalan redescribed from an unusual host, Mugil cephalus (Mugilidae), in the Arabian Gulf, with notes on histopathology and metal analysis. Parasite 25, 5

\section{PARASTE}

Reviews, articles and short notes may be submitted. Fields include, but are not limited to: general, medical and veterinary parasitology; morphology, including ultrastructure; parasite systematics, including entomology, acarology, helminthology and protistology, and molecular analyses; molecular biology and biochemistry; immunology of parasitic diseases; host-parasite relationships; ecology and life history of parasites; epidemiology; therapeutics; new diagnostic tools.

All papers in Parasite are published in English. Manuscripts should have a broad interest and must not have been published or submitted elsewhere. No limit is imposed on the length of manuscripts.

Parasite (open-access) continues Parasite (print and online editions, 1994-2012) and Annales de Parasitologie Humaine et Comparée (1923-1993) and is the official journal of the Société Française de Parasitologie. 